\title{
Brief Analysis of Urban Levee Management with Modern Information Technology - A Case Study in Yangzhong
}

\author{
Zhao Xueying ${ }^{1,2, a} \quad$ Zhao Xiaoqiu ${ }^{3} \quad$ Zhang Shunfu ${ }^{1,2}$ \\ ${ }^{1}$ Research Center on Flood and Drought Disaster Reduction of the MWR, Beijing 100038, China \\ ${ }^{2}$ Research Center on Flood and Drought Disaster Reduction, China Institute of Water Resources and Hydropower Research, Beijing 100038, China \\ ${ }^{3}$ Changjiang Institute of Survey, planning, Design and Research Limited CO, Wuhan Hubei 430010, China
}

\begin{abstract}
Yangzhong City often suffers from flooding of Yangtze River, typhoons and rainstorms, hence facing severe challenges in flood prevention. Meanwhile, with its rapid economic development and urban expansion, the population density increases within the levee, which imposes higher standards for levee safety. With modern information technology and introduction of the concept of whole-life cycle, a levee safety monitoring and early-warning system can be built to monitor the operation, provide technical support for safety management and operation.
\end{abstract}

\section{Historic Background of Yangzhong Levee}

Yangtze River stretches $107 \mathrm{~km}$ long in Yangzhong in its lower reaches, and its levee in Yangzhong is $120.3 \mathrm{~km}$ long, with $87.7 \mathrm{~km}$ along the mainstream and $68.1 \mathrm{~km}$ along the branches (as shown in Fig.1). The river in this area meanders in a zigzagged way. The levee on the right side of Taiping Sandbar is $44.2 \mathrm{~km}$. The sandbar, which is $31.0 \mathrm{~km}$ long and with a maximum width of $11.0 \mathrm{~km}$, is the largest sandbar in the lower reaches of Yangtze River.

Zhenjiang City started initiatives to manage Yangtze River in the 1950s, and has initiated successively the "First-Phase Project of Zhenjiang Section of Yangtze

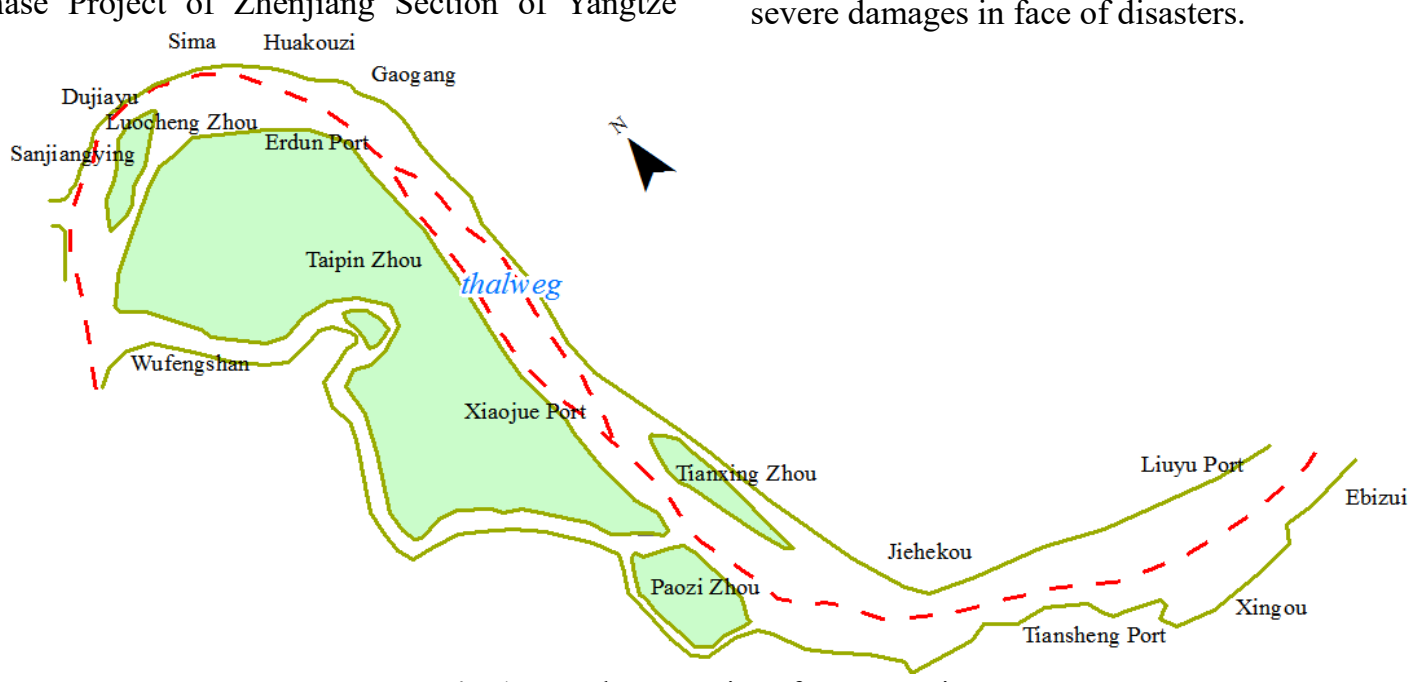

Fig. 1 Yangzhong Section of Yangtze River

\section{Challenges in Levee Management}

Yangzhong, a city under the governance of Zhenjiang City, Jiangsu, is located in the middle of the Yangzhong section of the lower reaches of Yangtze River. Surrounded by
River" (1983), "Second-Phase Project of Zhenjiang Section of Yangtze River" (1998), "Construction of Standard Levee of Yangtze River" (1998), and "Improvement Project of Yangzhong Section of Yangtze River" (2005). However, levee enforcement and river bank protection projects only focused on major engineering sections, and these levees, built centuries ago, contain potential dangers and have complicated geological conditions, subject to impact from human activities, alterations in fauna and flora as well as natural course changes. Because of these factors, it is difficult to eradicate the hidden risks and avoid disasters, causing severe damages in face of disasters.

\footnotetext{
Corresponding author: zhaoxy@iwhr.com
} 
public are attaching more importance to address how to ensure safe operation of the levee and how to reduce and control the risks of the levee.

\section{1) Immense Impact from Meteorological Disasters}

\section{like Flood and Typhoon}

Yangzhong, under the subtropical monsoon climate, witnesses frequent rainstorms and strong wind in the plum rain season. In addition, as it is where Huai River joins the lower reaches of Yangtze River, it is subject to diverse natural climatic disasters like floods, tides and rainstorms of Yangtze River and Huai River, and has recorded floods frequently in history. According to historic records [1], among 50 years since 1949, 17 years have seen the water level of Yangtze River in Yangzhong Section exceed 7.0m, once every three to four years on average; among these years, six years have witnessed the water level reaching $7.44 \mathrm{~m}$, the flood level during the 1954 Year Yangtze River Flood, and 18 years have seen Scale- 8 typhoons, in addition to 18 times of regional and temporary thunder storms and hails.

In August 1954, due to the interaction of the flood peak and tide of Yangtze River and Huai River, the water level in Yangzhong section reached $7.44 \mathrm{~m}$. At that time, most parts of the Yangzhong Levee cracked, collapsed and 140 breaches occurred along the levee, leading to inundation of 27 towns including Xinba and Sanmao, and 25000 local residents were displaced.

In July 1991, the highest water level reached $7.53 \mathrm{~m}$. Due to continuous rainstorms and tides, the levee was immersed in water and eroded by the rain for a long time. Consequently, one breach and 183 cases of cracks, collapse, pit-ponds and seepages occurred, causing 13 casualties.

In 1996, the highest water level in Yangzhong section reached a record high, $8.04 \mathrm{~m}$, leading to 77 sites of seepage that stretched $3.4 \mathrm{~km}, 41$ wave holes that stretched $13.1 \mathrm{~km}, 7$ breaches, and 7 sites of ruins on the stone revetment that stretched $0.92 \mathrm{~km}$. 14 water gates were on the verge of submersion, 6 sites on the wing walls of Dongxing Port Dam began to see water leakage, and there were pit-ponds on both sides of the wing walls of Xinglong Port Dam. Over ten levees including the levees of Xiaopaosha and Leigongju Sandbar suffered from inundation. The disaster affected an area of over ten thousand mu, collapsed 404 buildings and inundated 404 houses and 77 workshops and warehouses.

\section{2) Frequent Erosion, Siltation and River Bank}

\section{Collapse}

The Yangzhong section is a tidal course which features plenty of sandbars and a tangled network of rivers and ports. Due to the impact of upstream runoff and downstream tide, the flow and sediment conditions in this section are complex. Continuous river management projects in these years controlled the natural course changes, reduced alterations in the river's plane morphology and stabilized the river flow, but erosion and siltation still exist in some regions. In some regions, the mainstream thalweg of Yangtze River has been moving inward, and with the swash from wind and ship waves, the beach face of Yangtze River has retreated backward year by year, causing the thalweg to move towards the bank.
Because the levee faces the river, such a situation will impose direct threats to the integration and safety of the levee ${ }^{[2]}$. Over half a century since $1949^{[3]}$, there have been over 70 times of bank collapses in Yangzhong, which become a major challenge that threatens the levee's safety.

At five on the morning of November $8^{\text {th }}, 2017$, alarms went off at the bank $1.5 \mathrm{~km}$ up from Taizhou Bridge (as shown in Fig.2), and the main levee of Yangtze River began to collapse when it approached noon, and then the collapse stopped at around six in the afternoon. This bank collapse stretched 540 meters, with a maximum depth of 190 meters. 440 meters of the levee collapsed to a maximum distance of 51 meters beyond the levee, damaging an area of $146 \mathrm{mu}$ (101 mu inundated and 45 submerged), one culvert and nine resident buildings ${ }^{4}$. Some damages caused are shown in Fig. 3.
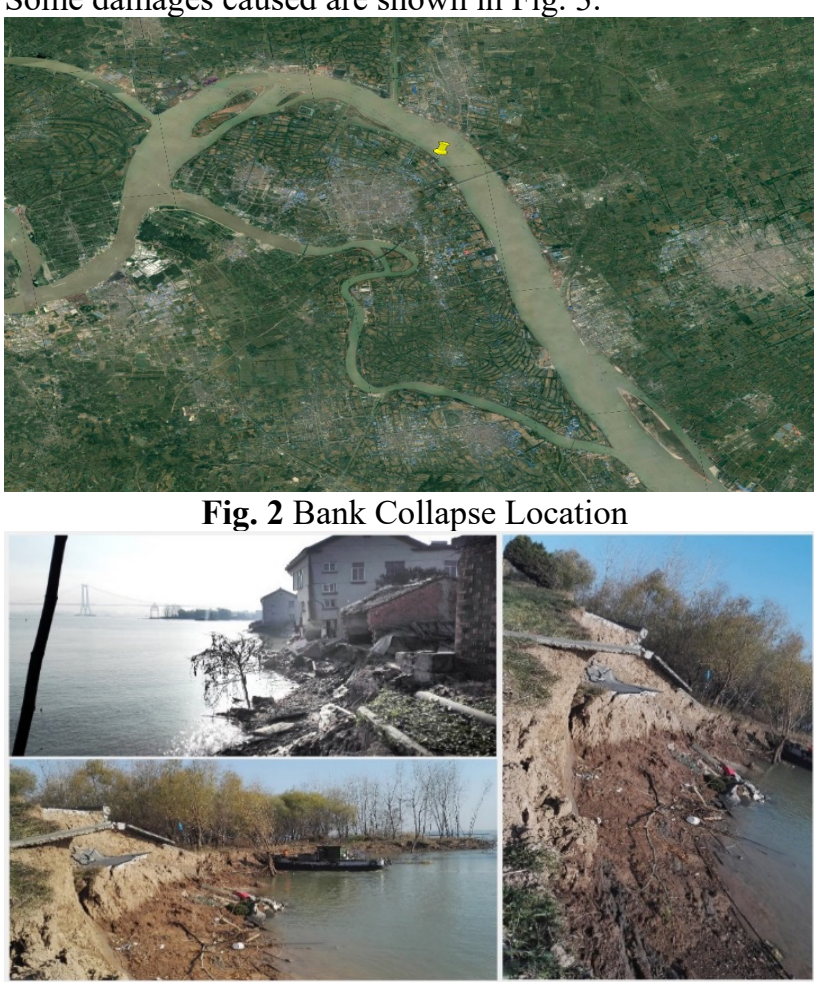

Fig. 3 Damages Caused by Bank Collapse

3) Emphasis on Construction, Negligence in Management

Water-related projects in Yangzhong adopt multilayered and multi-party management ${ }^{[2]}$. In such management mechanism which is insufficient and defective, construction is emphasized while management is neglected, and the water course management mode is to be improved [5]. The management facilities are outdated, and facilities for work, communication and transportation as well as for the management organization's production management fail to meet the standard of modern water conservancy projects. Moreover, there is no observing measures for levee projects or devices to monitor river regime underwater. The monitoring and management methods adopted for levee safety are outdated, and it merely relies on public involvement to ensure safety during the flood seasons, which is costly and inefficient.

\section{Objective and Content of Construction}


In these years, with more and more devoted to construction of the Yangzhong levee, the flood-prevention performance and safety level of some parts of the levee have been improved. However, because of uncertainties of external conditions and the project, the safety level changes with time and occurrence of such disasters as bank collapse, piping and overflow is random. Therefore, it is necessary to make safety assessment and risk analysis based on real-time monitoring of rain, water and project conditions as well as the dynamic changes of the project so as to facilitate the authorities' decision-making in management and emergency control.

Based on the status quo of the levee and practical needs and with the objectives of improving the level of monitoring, early-warning, assessment, management and decision-making of levee safety management, a management system can be built through advanced communication and computer network technology, information collection technology, monitoring technology, data management technology, information application technology, in addition to cloud computing, big data, the hydrodynamic model and mobile Internet, so as to realize information collection, monitoring, forecast, early warning, assessment, project management and decisionmaking through conferences. Application of project safety assessment and safety forecast mathematical models can enable comprehensive monitoring and assessment of levee project safety. With the models, we can monitor the levee's conditions in real time to ensure its safety, give full play to its role in flood control and in benefiting the society. Also, the models can help identify the hidden risks in advance, find measures for improving operation and maintenance, and develop an all-round, multidimensional system for real-time monitoring of the levee so as to ensure the levee's safe operation and protect people's life and property.

Construction of the early-warning and safety monitoring system of the levee includes the following five aspects: firstly, to establish the basic database; secondly, to build an all-round safety monitoring and information collection system for the levee; thirdly, to build a onemap-based all-element dynamic real-time monitoring system; fourthly, to make two-dimensional inundation simulation, risk analysis and identify replacement plans after levee collapses; the fifth aspect is to realize forecast, early-warning, safety analysis and assessment of the levee; the sixth is to develop a mobile app and extend reality application; the seventh is to build a comprehensive operative platform to realize whole life-cycle management of the monitoring system.

The levee safety early-warning and monitoring system comprises the following key technical aspects.

(1) Before the flood season begins, UAVs can be used to make topographic surveys, and through application of multi-beam or sonar measuring techniques, the scouring conditions along the bank can be observed to identify collapse-prone sites and put forward collapse-prevention measures accordingly. With high-density electrical prospecting apparatus, transient electro magnetometer, frequency-domain electro magnetometer, geological radar, surface wave detector, potential risks in the levee can be detected, and through professional models and analysis techniques, safety assessment of the levee can be made to identify the engineering safety risks efficiently and propose countermeasures accordingly.

(2) New technological devices can be used for floodcontrol inspection and emergency management when the water level is high in flood seasons. Through portable thermal infrared imagers or remote temperature measuring devices mounted on vertical-moving fixedwing UAVs, the difference of the temperature field can be detected to identify areas with potential risks of seepages and piping, and by way of inspection by engineers, risks for seepage can be identified promptly. In light of potential risks of seepage, landslide, bank collapse, piping and scouring, scenario analysis of levee disaster development and flooding can be made to put forward plans for emergency management and release earlywarning information to professionals and the public through modern information technology.

(3) As for post-disaster rescue, modern information technology can be utilized to provide real-time information of rainfall and flood so as to provide basis for flood-control decision-making.

\section{Conclusion}

By introducing the concept of whole life-cycle into levee safety management, with modern information technology and engineering protection measures which focus on collection and transmission of multi-source information about levee construction, rainfall and disasters, and through modern information technology, space science and surveying techniques, we can build an integrated safety management system that incorporates such functions as levee safety analysis, disaster assessment, rainfall monitoring and early-warning, which can improve daily and emergency management of the levee project, and provide technical support for efficient levee safety management and quick response to emergencies.

\section{Acknowledgments}

This paper is supported by National Key R\&D Program of China (2017YFC1501202).

\section{Reference}

1. Report on Urban Flood Control Planning of Yangzhong. Shanghai Waterway Engineering Design and Conuslting Co., Ltd.

2. Hu Chunyan, Hou Weiguo. Research on Mainstream Course Management and Planning in Middle and Lower Reaches of Yangtze River. Yangtze River, 44 (2013)52-55.

3. Hong Dalin, Li Chunchao, Xie Rui et al. Analysis of Riverbed Evolution of the Yangzhong Section of Yangtze River. Urban Roads Bridges \& Flood Control, 9 (2007)45-49.

4. Levee Failures in Yangzhong of Zhenjiang City, Jiangsu.

http://www.sohu.com/a/203175931_123753 
5. Wang Zhiguo. Research on Existing Problems in Management of Yangtze River Levee and Solutions.
Industry B, 3 (2016)179-180. 